\title{
Maxillary Odontogenic Keratocyst Masquerading A Periapical Cyst
}

\section{JAYAPRASAD ANEKAR ${ }^{1}$, KRISHNA S. KUMAR*2, DEEPIKA NAPPALLI ${ }^{*}$, IVIN ELSA JOHN}

Odontogenic Keratocysts previously termed, as keratocystic odontogenic tumor is a developmental odontogenic cyst. It is one of the most commonly occurring odontogenic cyst and is characterized by its aggressive behaviour, high recurrence rate and association with syndromes. A case of odontogenic keratocyst occurring in the maxillary anterior region is described here with emphasis on the importance of advanced imaging modalities like computed tomography in the diagnosis and treatment planning.

KEYWORDS: Maxilla, Odontogenic keratocyst, Computed Tomography

\section{INTRODUCTION}

Odontogenic keratocyst previously classified under benign odontogenic tumors was again reclassified into an odontogenic cystic lesion by WHO in 2017. It has many distinguished clinical and histological features. They occur more commonly in the mandible. Maxillary OKCs are rare and is often misdiagnosed due to its varying clinical and radiographic appearances. Even though conventional radiographs like intraoral radiographs and panoramic radiograph can provide necessary information, advanced imaging modalities can help clinicians in accurate diagnosis and also aids in treatment planning. The present case is of a maxillary OKC occurring in relation to an endodontically treated tooth with emphasis on the characteristic features seen on computed tomography, which helps in differentiating with other lesions.

\section{CASE HISTORY}

A 32-year-old male patient reported to the Department of Oral Medicine and Radiology of our institution, complaining of swelling in gums of upper anterior teeth region since 2 months. He gave a history of occasional pus discharge from the swelling while pressing it. There was no increase in the size of the swelling since he first noticed it. He also gave a history of a swelling in the same region, which was removed, and root canal treatment of the affected tooth was done 10 years ago. There was no history of pain and his medical and family history was not significant.

Intraoral examination revealed a swelling in the attached gingiva and labial vestibular sulcus in relation to maxillary left lateral incisor and canine region, which was confirmed on palpation. It was roughly round in shape of $0.5 \mathrm{~cm}$ in diameter, nontender, soft in consistency, compressible but not reducible and non-pulsatile. Left maxillary canine was slightly displaced distally. (Figure 1)

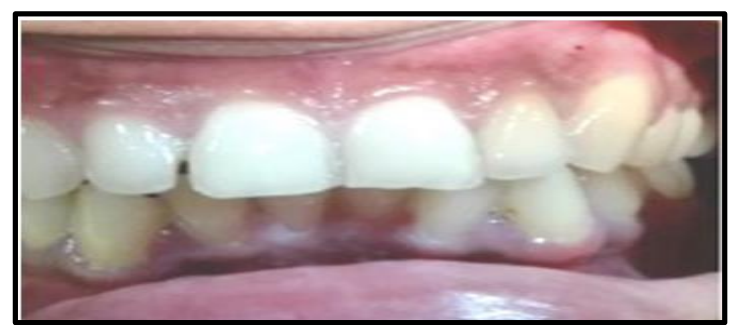

Figure 1. Slightly Distally Displaced Left Maxillary Canine

Maxillary left lateral incisor was restored and it was tender on percussion. No other relevant intraoral findings observed.

Based on history and clinical findings, it was provisionally diagnosed as recurrent periapical cyst in relation to non-vital maxillary left lateral incisor.

Investigations: Electric pulp vitality test was performed which revealed that 21, 23, 24 and 25 were vital. Aspiration of the swelling revealed a pale yellow fluid mixed with pus.

Maxillary anterior occlusal radiograph revealed a welldefined radiolucency with sclerotic border measuring about $3 \times 3 \mathrm{~cm}$ extending from the mid radicular portion of mesial aspect of 21 to the periapical region of 25 . Coronal and radicular radioopacity in the pulp space of 22 revealed endodontic treatment. (Figure 2 (a) and 2 (b)).

CT scan of paranasal sinuses showed a well-defined soft tissue density lytic lesion in the left maxillary alveolar region involving the apices of the left upper 
central incisor, lateral incisor and canine suggestive of a cystic lesion with left oro-antral fistula. (Figure 3)

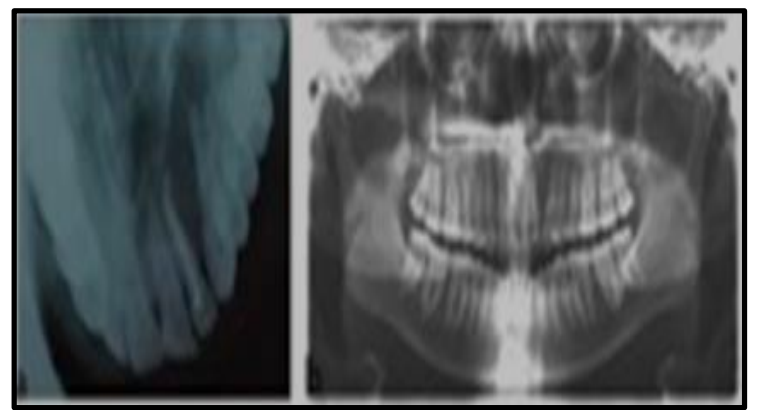

Figure 2(a). Maxillary anterior occlusal radiograph revealing a well-defined radiolucency extending from the midradicular portion of 21 to periapical region of 25 and 2

(b). Similar radiolucency as seen in occlusal radiograph

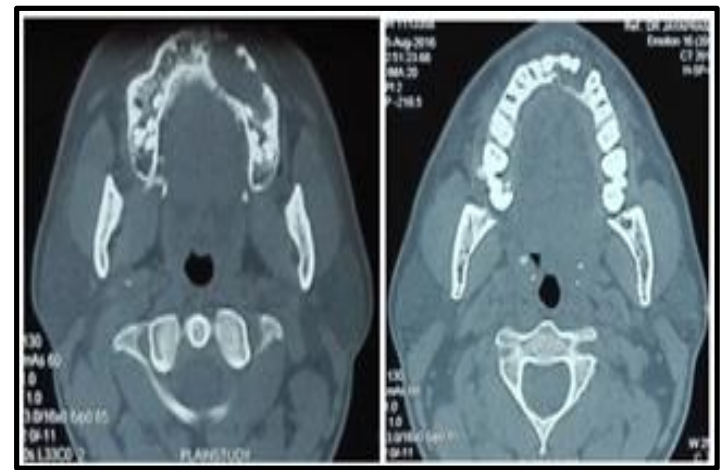

Figure 3. Cystic Lesion with Left Oro-Antral Fistula

\section{DIFFERENTIAL DIAGNOSIS}

The differential diagnosis of nasolabial cyst and adenomatoid odontogenic tumour in 22 and 23 region was made due to the similar clinical presentation of the lesion. Radiographic differential diagnosis of radicular cyst, paradental cyst and lateral periodontal cyst were given because of the similar radiographic presentation.

\section{TREATMENT}

Complete excision of the lesion was done under general anaesthesia (Figure 4).

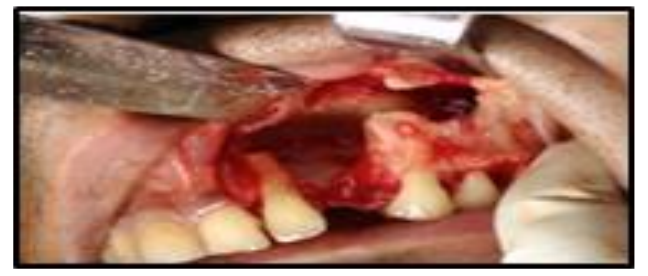

Figure 4: Surgical Excision of the Lesion
The histopathological examination of the specimen revealed cystic cavity lined by epithelium and supported by connective tissue wall. Epithelium was parakeratinized stratified squamous type and exhibits surface corrugation. Basal cells exhibited hyperchromatism and palisading. Connective tissue capsule consisted of collagen fibres with spindle shaped fibroblasts, focal infiltration of predominantly chronic inflammatory cells, blood vessels filled with RBC's and areas of extravasated RBC. Areas of bony trabeculae and part of the maxillary sinus's pseudo stratified ciliated epithelium were also noticed (Figure $5)$.

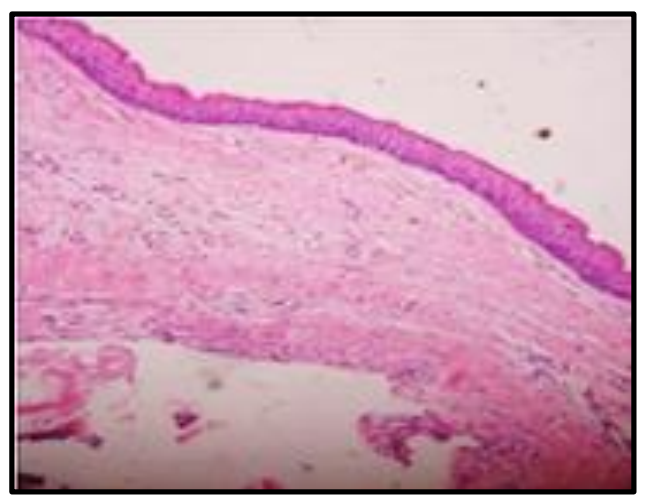

Figure 5. Histopathological Examination of the Specimen

The histopathological diagnosis of the lesion was given as odontogenic keratocyst.

\section{OUTCOME AND FOLLOW UP}

Wound healing was uneventful and the patient is under regular follow up and no recurrence observed till date.

\section{DISCUSSION}

Odontogenic Keratocysts (OKCs) are developmental odontogenic cysts of epithelial origin, first identified and described in 1876. ${ }^{1}$ In 1992, the World Health Organization (WHO) listed OKC as the preferred terminology as the cyst contains keratinized lining. ${ }^{2}$ In later years, published reports have influenced WHO to reclassify the lesion as a tumour and was known as keratocystic odontogenic tumour(KCOT).

But recently it is again included in the odontogenic cyst category in the $4^{\text {th }}$ edition WHO 2017 classification of odontogenic and maxillofacial bone tumors. It was concluded that most cases of KCOT behave clinically as non-neoplastic lesions and may be 
treated as cysts. There was consensus that it should be reclassified as OKC until there is more definitive evidence for classifying them as KCOT. ${ }^{3}$

OKC is a relatively common odontogenic cyst with a reported incidence of 7 to $11 \%$ among all oral developmental cysts. It has a wide age range of occurrence ranging from 10 to 40 years of age with a slight male predilection. ${ }^{1}$ They are most often found in the mandible by a 2:1 margin over the maxilla. The most common sites of occurrence are the mandibular third molar and ramus region, followed by the anterior maxilla. In the anterior maxilla region it was found to be more commonly seen in canine area. ${ }^{5}$

Ali and Baughman reported that in the maxillary canine region $\mathrm{OKC}$ was mentioned as a diagnostic possibility by only 31.5 percent of the clinicians. The most popular clinical diagnoses were periapical cyst/granuloma and lateral periodontal cysts. ${ }^{5} \mathrm{OKC}$ may appear as a small unilocular radiolucency near an endodontically treated or a non-vital tooth and may present with signs of inflammation like swelling, pus discharge etc., which leads to the misdiagnosis of an inflammatory lesion ${ }^{6}$ and these features are seen in the present case also.

Panoramic and intraoral radiographic techniques can provide necessary diagnostic information's regarding OKCs. ${ }^{7}$ But computed tomography provides accurate assessment of the true extent of the lesion and its relationship to important anatomic structures, which also helps in surgical planning. ${ }^{8,9}$ In maxillary lesions Computed tomography(CT) scan is very essential if we suspect a sinus involvement. Typical features of OKC, which differentiate it from other lesions in a CT scan, are the spiculation at the internal margins and the lack of significant expansion. Luminal area of the cyst may appear cloudy due to presence of desquamated keratin and is termed as cloudy or milky way lumen. ${ }^{9}$ It can also appear with high attenuation in the CT images. It may be due to the high protein content, dense keratin in the lumen, calcification or haemorrhage. If high attenuation represents calcification we should consider Gorlins cyst, Pindborgs tumor and adenomatoid odontogenic tumor in the differential diagnosis. In such cases areas of calcification will be demonstrated on histopathological examination. Parakeratinized OKCs may have high attenuation than the orthokeratotic subtype of odontogenic cysts. But this may vary and is unlikely to help between the two variants. ${ }^{10}$

On Magnetic resonance imaging (MRI), it typically presents with an intermediate or high signal intensity in $\mathrm{T}_{1}$ weighted images and heterogenous low to high intensity signal in $\mathrm{T} 2$ weighted images. This might be due to the presence of desquamated keratin, or the cholesterol content present in the fluid. Presence of a secondary infection might also affect the signal strength. ${ }^{11}$

Cone beam computed tomography (CBCT) could also be done which provides dimensionally and anatomically accurate images of oral and maxillofacial pathologies. Although it is associated with less radiation exposure than $\mathrm{CT}$, there is limitation as soft tissue boundaries may be better identified in CT and are more consistent than in $\mathrm{CBCT}$. ${ }^{11}$

Ultrasonography can be used as a supplementary imaging modality for intraosseous lesions. It reveals a dense cystic lesion with no flow detected on Color Doppler examination for OKC. But it is not useful in cases where there is thick intact cortical bone. ${ }^{12}$

Diagnosis of OKC is a challenge radiologically as many other lesions mimic the appearance of OKC. Most frequently it is misdiagnosed as a dentigerous cyst followed by lateral periodontal cyst, radicular cyst and residual cyst. Hence only half or less is identified or suspected radiographically. ${ }^{9}$

Histopathologically OKCs demonstrate a thin friable wall, which is difficult to be separated from bone. Cystic lumen consists of clear fluid, which may be keratinaceous debris on microscopic examination. Luminal surface has parakeratotic epithelial cells arranged in a wavy or corrugated pattern. Basal cells are arranged in tombstone pattern of hyperchromatic cuboidal or columnar epithelial cells. Small islands of odontogenic epithelium may be seen in fibrous wall

and are termed as satellite cyst or daughter's cyst. ${ }^{13}$ Abtropfung/dropping down phenomenon of the epithelial elements in the connective tissue wall may be seen. ${ }^{9}$ Typical features of the cyst may be lost in inflammation.

Earlier microscopic orthokeratinzed variant was considered as a subtype of OKC. But it is now regarded as a separate odontogenic cyst as it has different 
clinicopathological behaviour. ${ }^{33}$

Multiple OKCs are associated with syndromes like, Gorlin goltz syndrome, Marfan syndrome, EhlersDanlos syndrome, Noonan's syndrome. ${ }^{14}$

OKCs can be treated either by marsupialisation or enucleation. Marsupialisation is indicated when there is proximity of vital anatomical structures or if the tooth has to be saved. Marsupialisation followed by enucleation can be done which will help in removing the thin epithelial lining. ${ }^{15}$ But conservative treatment may be associated with high recurrence rate and patient compliance is required. Application of Carnoy's solution can be done which removes the epithelial remnants and dental lamina by maintaining the bony architecture. ${ }^{16}$ In cases with multiple OKCs or large cysts resection and reconstruction with grafts may be required. ${ }^{17}$

Recurrence rate of OKC ranges from $16-30 \%{ }^{17}$ It is affected by various factors including thin and friable epithelial lining, presence of daughter cysts, poor surgical treatment and finger like extensions of cyst into the underlying bone. Maxillary OKCs have a higher risk of penetration of skull base. ${ }^{15}$ They are also associated with high risk of infection due to close proximity with maxillary sinus. ${ }^{18}$ Hence regular follow up with radiographic examination has to be done.

\section{REFERENCES}

1. Philipsen HP. Om keratocyster (kolesteatom) I kaeberbe. Tandlaegebladet. 1956;60:963-80.

2. Blanchard SB. Odontogenic Keratocysts: review of the literature and report of a case. Journal of Periodontology 1997;68(3):306-11.

3. Passi D, Singhal D, Singh M. Journey of OKC from cyst to tumor to cyst again: Comprehensive review with recent updates on WHO classification. International Journal of Current Research 2017;9(7):54080-6.

4. Forssel K, Forssel H, Kahnberg. Recurrences of keratocysts in a long term follow-up study. Int J Oral Maxillofac Surg. 1988; 17(1):25-8.

5. Ali M, Baughman RA. Maxillary odontogenic keratocyst a common and serious clinical misdiagnosis. J Am Dent Assoc 2003;134:877-83.

6. Garlock JA, Pringle GA, Hicks ML. The odontogenic keratocyst: a potential endodontic misdiagnosis. Oral Surg Oral Med Oral Pathol Oral Radiol Endod 1998;85:452-6.
7. Daniel Antunes F, Daniela Araujo V, Alisson Luis D'Afonseca S, Vinicius Antunes F. Maxillary odontogenic keratocyst: a clinical case report. Rev Gauch Odontol. 2015;63(4):484-8.

8. Cotti E, Vargiu P, Dettori C, Mallarini G. Computerized tomography in the management and follow-up of extensive periapical lesion. Endod Dent Traumatol. 1999; 15(4):186-9.

9. Langlais PR, Langland EO, Nortje CE. Diagnostic Imaging of the Jaw. Williams \& Wilkins; 1995: 331-332. 10. Yontesu K, Bianchi GJ, Troulis JM, Curtin DM. Unsual CT appearance in an odontogenic keratocyst of mandible: Case report. AJNR Am J Neuroradiol 20o1; 22:1887-9.

11. Gamba Tde O, Flores LI, Pinto AB, Costa AL, Moraes ME, Lopez SL. Keratocystic odontogenic tumor: Role of cone beam computed tomography and magnetic resonance imaging. Gen Dent 2016;64(1):36-9.

12. Sumer PA, Sumer M, Celenk P, Danaci M, Gunhen O. Keratocystic odontogenic tumor:case report with $\mathrm{CT}$ and ultrasonography findings. Imaging sciences in dentistry 2012;42:61-4.

13. Neville BW, Damm DD, Allen CM, Bouquot JE. Oral and Maxillofacial Pathology. $2^{\text {nd }}$ Edition. Philadelphia: WB Saunders; 2002:447-9.

14. Ghom GA, Ghom AS. Textbook of Oral Medicine. 3rd edition. New Delhi: Jaypee Brothers; 2014: 250-3. 15. Cawson, RA, Odell EW. (2008). Cawson's essentials of oral pathology and oral medicine. $8^{\text {th }}$ edition. Edinburgh: Churchill Livingstone; 2018:124-7.

16. Lone PA, Singh M, Johar HS. Treatment Modalities of Odontogenic Keratocyst of Maxilla and Mandible: Our Experience. World J Dent 2015; 6(4):208-12.

17. Chandrashekhar B, Prashant MC, Bharat S, Pandilwar PK. Prevalence, Treatment and Recurrence of Odontogenic Keratocyst in Central India J Maxillofac Oral Surg 2010;9(2):146-9.

18. Blanas N, Freund B, Schwartz M, Furst I.M, Systematic review of the treatment and prognosis of the odontogenic keratocyst Oral Surg. Oral Med. Oral Pathol. Oral Radiol Endod. 2000;90:553. 
Source of support: Nil, Conflict of interest: None declared

Cite this article as:

Anekar J, Kumar KS, Nappalli D, John IE. Maxillary Odontogenic Keratocyst Masquerading A Periapical Cyst. Int Healthcare Res J 2018;2(6):133-137. doi: 10.26440/IHRJ/02_06/196

\section{AUTHOR AFFILIATIONS:}

1. Professor and Head, KVG Dental College and Hospital, Sullia DK, Karnataka

2. Assistant Professor, Amrita School of Dentistry, Amrita Vishwavidyapeetham, Edappily, Kochi, Kerala

3. Reader, KVG Dental College and Hospital, Sullia DK, Karnataka

4. Former Postgraduate Student, KVG Dental College and Hospital, Sullia DK, Karnataka

\section{*Corresponding Author:}

Dr. Krishna S. Kumar Assistant Professor

Amrita School of Dentistry Amrita Vishwavidyapeetham Amrita Nagar, Edappally Ernakulam, Kerala 682041
For article enquiry/author contact details, e-mail at: manuscriptenquiry.ihrj@gmail.com 